\title{
FINITE ELEMENT ANALYSIS OF TI-6AL-4V ELI AND ZIRCONIA BIO-INERT MATERIAL USED IN MOLAR TOOTH DENTAL IMPLANT APPLICATION
}

\author{
Sharanraj. $\mathrm{V}^{1}$ and Dr. C.M. Ramesha ${ }^{2}$
}

\begin{abstract}
Ti-6AL-4V ELI and Zirconia are the important bio-inert materials used in the field of dental implant due to their unique characteristics of minimal interaction with surrounding tissue. This paper presents the typical Finite element method (FEM) is an effective approach for analysis of dental implant and dental structures. In the present work, 3 dimensional modeling of molar tooth was generated by CATIA V5 software and analysis were carriedout by commercial FEA software Ansys 14.5 to evaluate the displacement, strain, stress, fatigue life and factor of safety in the proximal region of Ti-6Al-4V ELI and Zirconia molar tooth implant under static load condition of 50, 100, 150, 200, 250 and 300 newton. The results show that the displacement, strain and stresses, fatigue life and factor of safety were within the material admissible limits for Zirconia. Hence the study reveals that Zirconia is an alternate biomaterial suitable for dental implants.
\end{abstract}

$$
\text { Keywords - Bio-inert material, Ti-6Al-4V ELI, Zirconia, FEM. }
$$

\section{INTRODUCTION}

Biomaterial is a non-viable material used in the field of medical dental implantation, which is intended to interact with biological system. A dental implant is an artificial substitute for the replacement of missed tooth. Based on the biological interaction with material, biomaterials are categorized into three types. i.e., Bio-inert materials, Bio-active materials and Bio-resorbable materials. Bio-inert materials are those materials which has minimum interaction with the surrounding tissue namely Titanium alloy (Ti-6AL-4V ELI) and Zirconia [1]. Bio-active materials are those materials when placed in a human body interact with the surrounding tissues namely glass, ceramics and Bioglass. Bio-Resorbable materials are those materials which start dissolving when placed in human body and slowly replaced by the advancing tissue namely bone. But today Bio-inert materials have been extensively used in dental implants, due to their unique characteristics like good biocompatibility, high yield strength and high corrosion resistance [2].

Dental Anatomy is a field of anatomy dedicated to the study of tooth structure and as shown in Fig.1. A dental

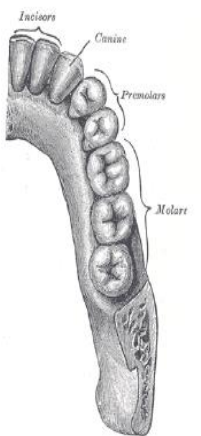

(a)

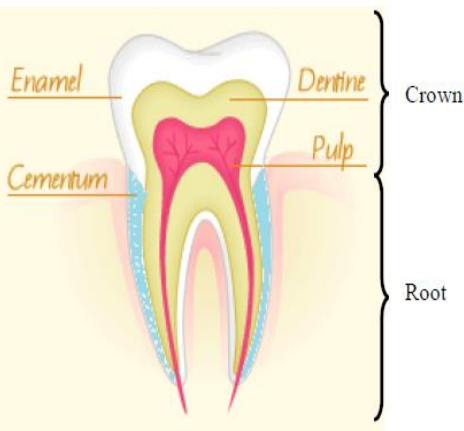

(b)

\footnotetext{
${ }^{1}$ Department of Mechanical Engineering M.S. Ramaiah Institute of Technology, VTU, Bangalore - 560054, Karnataka, India
}

${ }^{2}$ Department of Mechanical Engineering M.S. Ramaiah Institute of Technology, VTU, Bangalore - 560054, Karnataka, India 
Fig.1. Dental Anatomy (a) Molar tooth location (b) Molar tooth structure [7].

implant is an artificial substitute for the root of a tooth that is placed into the jawbone, and ultimately fuses with the bone in order to support a replacement tooth. The teeth are the hardest substances in the human body. Besides being essential for chewing, the teeth play an important role in speech [1]. After a tooth has been damaged or decayed, restoration of the missing structure can be achieved with a variety of treatments from variety of materials, including Titanium alloy (Ti-6Al-4V ELI) and Zirconia are small restorations placed inside a tooth are referred to as intracoronal restorations.

These restorations may be formed directly in the mouth or may be cast using the lost-wax technique, such as for some inlays and onlays. When larger portions of a tooth are lost, an extracoronal restoration may be fabricated, such as a crown and screw or implant, to restore the decayed tooth. A normal adult mouth has 32 teeth, which have erupted around age 18. Parts of the teeth include: Enamel, Dentin, Pulp Cavity, Crown, Root, Cement, Gum Tissue, Incisors, Canines, Premolars and Molars [1]. Molar are flat tooth located at rear end of the mouth for the best grinding of food and the only tooth which can withstand maximum load upto 300N. Hence 3D modeling and Finite element analysis is carriedout on molar tooth by applying Ti-6AL-4V ELI and Zirconia material properties in the present work.

As in [10]. Author has aimed the study to provide a detailed description of crown-size dimension in the deciduous dentition of people and to compare the findings with those of other populations. Measurement of mesiodistal (MD) and buccolingual (BL) crown diameters were obtained from dental casts of 84 males and females aged 2.9 years to 18 years. The differences in crown size (MD and BL diameters) between the right and left sides of the dental arch were not significant.Ti-6Al-4V ELI composition consists of Ti $89 \%$ wt, $\mathrm{Al} 6 \%$ wt and $\mathrm{V} 4 \%$ and is widely used for implants and other porous surface-coating and contains impurities (N, 0.13\% O, Fe, H and C). Extra Low Interstitials (ELI) includes impurities increasing interstitial content that increase strength and fatigue limit. (N increases hardness, $\mathrm{O}$ increases tensile strength), but has unsatisfactory wear.

Ti-6Al-4V ELI having yield strength $114 \mathrm{GPa}$ is widely used in dental implants due to their unique characteristics such as lower modulus, superior tissue compatibility and high corrosion resistance. But then the presence of vanadium in Ti-6Al-4V ELI alloy will cause long health related problems [6]. Hence it is no longer the case that titanium is considered as completely bio-inert material. In contrast, titanium is thought to be the" New Allergen" as demonstrated by several reports and studies [1]. Titanium has entirely replaced other metals in dental implants. Titanium is also widely used in oral and maxillofacial surgery to form other devices such as grids, membranes, plates, screws and tooth. The mechanical properties can be enhanced when titanium is alloyed, but sometimes deteriorates the corrosion resistance properties and constituent release can be substantially reduced with surface treatments of titanium or its alloy. The author concluded that titanium release from the devices stops only after bone is laid down on the titanium surfaces and titanium release does not seem to interfere with the osteogenic process but perhaps may interact with it [8].

Zirconia $\left(\mathrm{ZrO}_{2}\right)$ ceramics have superior mechanical properties for biomedical applications compared to other ceramics, exemplified by higher fracture toughness, higher flexural strength, and lower Young's modulus 205 $\mathrm{GPa}$ (giga pascal). There are two types of zirconia ceramics commonly used for surgical implants: yttriastabilized tetragonal zirconia and magnesium oxide partially-stabilized zirconia [4]. Partially stabilized zirconia is practically used today in manufacturing of dental crown. As in [12] author has a focus of interest in implant dentistry in the application of ceramic materials for the fabrication of implant abutments as well as for dental implants. When compared to Zirconia ceramic, the enhanced strength of zirconia was explained by microstructural differences such as higher density, smaller particle size and had performed FEM analyses of sound and restored teeth to evaluate stress distribution assessment. This method is efficient approach to mechanical and fracture behavior of systems with complex geometry and with materials with different mechanical properties submitted to different loading modes [13].

FEM analysis is a powerful tool to characterize dental systems in their different functional conditions, being of great importance to both dentists and engineers [2]. In vitro tests of sound and restored teeth are being submitted to a static and cyclic loading under functional conditions by biomaterials group to validate the numerical results obtained from FEM. As in [11] author has investigated the biomechanical behavior of a threaded functionally graded biomaterials dental implant surrounding bone system under static and harmonic forces by using a three-dimensional finite element method. The interaction of the implant and the supporting bone tissues is considered. Three contact conditions at the implant-bone interface are used to model different osseointegration stages. A comprehensive parametric study was conducted to highlight the influence of the material properties and the osseointegration quality on the maximum von-Mises stress, deformation distribution and natural frequencies. 


\section{Finite Element And Experimental Procedure}

\section{A. Geometric Modeling}

The first step in FEM is a geometric modeling [3]. In this step the three dimension (3D) model of molar tooth with implant is generated by using CATIA V5 software is illustrated in Fig. 2(a) and 3D model is converted into step file format (STP) shown in Fig. 2(b).

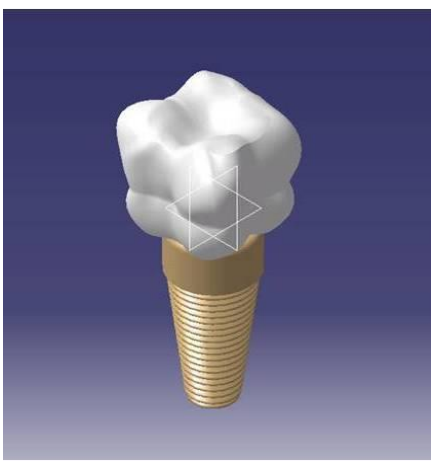

(a)

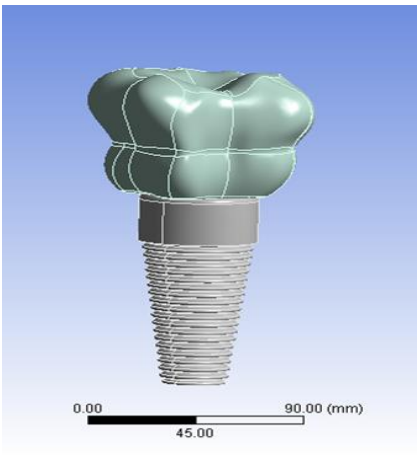

(b)

Fig. 2(a) 3D model of molar tooth with implant in CATIA, (b) 3D model converted into STP.

Geometrical dimension of molar tooth are validated against actual tooth and implant by measuring key dimension listed in Table 1.

Table 1: Comparison of key dimension of tooth

\begin{tabular}{|l|l|l|}
\hline $\begin{array}{l}\text { Molar tooth with implant } \\
\text { Dimension }\end{array}$ & $\begin{array}{l}\text { Actual } \\
\text { molar } \\
\text { tooth }\end{array}$ & $\begin{array}{l}\text { Geometric modeling } \\
\text { by CATIA V5 }\end{array}$ \\
\hline Height of Crown (mm) & 07 & 07 \\
\hline Perimeter of Crown at middle (mm) & 24 & 24.015 \\
\hline Height of implant (mm) & 10 & 10 \\
\hline Perimeter of Implant (mm) & 15.5 & 15.71 \\
\hline Pitch of implant thread (mm) & 0.40 & 0.39 \\
\hline
\end{tabular}

\section{B. Meshing}

Meshing involves discretization of geometric model in to finite discrete elements. Ansys provides various options to produce 3D mesh on STP format of molar tooth model illustrated in Fig. 3.

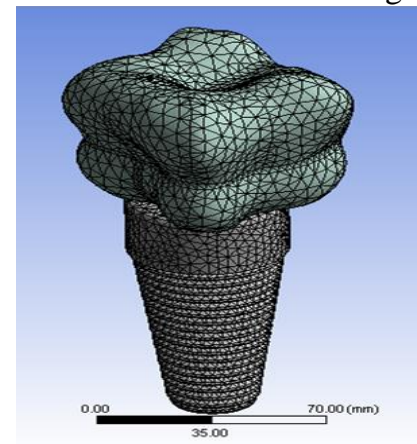

Fig. 3. Tetrahedron meshed molar tooth with implant in ANSYS 14.5. 


\section{Finite Element Analysis Of Ti-6al-4v Eli And Zirconia Bio-Inert Material Used In Molar Tooth Dental Implant Application

Meshing details of molar tooth with implant and its dimension is listed in Table 2. In this paper, mesh has been demonstrated considering implant grain boundaries and using implicit solution know as patch confirming method. The results for the required number of elements and nodes for mesh are achieved after examining the convergence. If the result in the implant job module is not convergent the mesh size must be changed until the proper results are attained.

Table 2: Meshing details of molar tooth with implant and its dimension.

\begin{tabular}{|c|c|}
\hline $\begin{array}{c}\text { Meshing details of } \\
\text { molar tooth with implant }\end{array}$ & Dimension \\
\hline Element size & $3 \mathrm{~mm}$ \\
\hline Number of Elements & 25530 \\
\hline Number of Nodes & 43820 \\
\hline Element shape & Tetrahedron \\
\hline Method & Patch Confirming \\
\hline
\end{tabular}

\section{Material Properties}

In this study, the assumption was made that the materials (Ti-6Al-4V ELI and Zirconia) were homogenous, isotropic and that had elastic behavior characterized by three material properties i.e., Density, Young's modulus and poission's ratio. The physical and mechanical properties of Ti-6Al-4V ELI and Zirconia Bio-inert materials are depicted in the Table 3 [9].

Table 3: Physical and mechanical properties of Ti-6Al-4V ELI and Zirconia Bio-inert material.

\begin{tabular}{|l|l|l|l|}
\hline \multirow{2}{*}{ Material } & \multicolumn{2}{|l|}{ Material Properties } \\
\cline { 2 - 4 } & $\begin{array}{l}\text { Density } \\
\text { in } \\
\mathbf{k g} / \mathbf{m}^{\mathbf{3}}\end{array}$ & $\begin{array}{l}\text { Young's } \\
\text { Modulus in GPa }\end{array}$ & $\begin{array}{l}\text { Poisson } \\
\text { 's Ratio }\end{array}$ \\
\hline $\begin{array}{l}\text { Molar Tooth (Ti-6Al-4V ELI) } \\
\text { Implant (Ti-6Al-4V ELI) }\end{array}$ & 4430 & 114 & 0.34 \\
\hline $\begin{array}{l}\text { Molar Tooth (Zirconia) } \\
\text { Implant (Zirconia) }\end{array}$ & 5680 & 205 & 0.23 \\
\hline
\end{tabular}

\section{Loads and Boundary Conditions ( $L B C$ 's)}

The assumed different loads and boundary condition on Ti-6Al-4V ELI and Zirconia Bio-inert materials are as shown in the Table 4. A boundary condition is the application of load and constraint. Boundary condition includes simulated compression uniformly distributed load of $50 \mathrm{~N}$ to $300 \mathrm{~N}$ at every $50 \mathrm{~N}$ interval, at $90^{\circ}$ along the y axis, were applied to the top surface of molar tooth with implant and zero displacement constraint were placed along $\mathrm{X}$ and $\mathrm{z}$ axis boundaries of the model to ensure an equilibrium solution. i.e., for minimum load $(\mathrm{Fx}, \mathrm{Fy}, \mathrm{Fz})=(0,-50,0)$ and for maximum load $(\mathrm{Fx}, \mathrm{Fy}, \mathrm{Fz})=(0,-300,0)$. 300N load distribution on molar tooth with implant shown in Fig. 4.

Table 4: Different loads and boundary condition applied on Ti-6Al-4V ELI and Zirconia Bio-inert material.

\begin{tabular}{|l|l|l|}
\hline Material & Load in Newton & Boundary Condition \\
\hline Titanium alloy (Ti-6Al-4V ELI) & $50,100,150,200,250$ and 300N & Static \\
\hline Zirconia( $\left(\mathrm{Zro}_{2}\right)$ & $50,100,150,200,250$ and 300N & Static \\
\hline
\end{tabular}



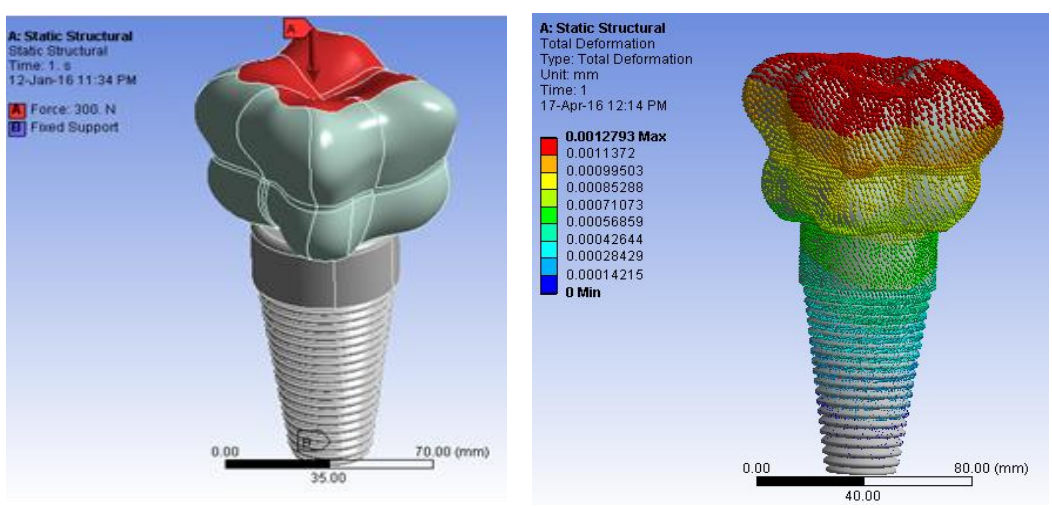

Fig. 4. 300N load distribution on molar tooth with implant.

\section{E. Analysis}

Finite Element Analysis (FEA) solver Ansys Product Launcher R14.5 is used to determine total deformation, maximum principal strain, maximum principal stresses, fatigue life and factor of safety for Ti-6Al-4V ELI and Zirconia bio-inert material at different loading conditions i.e., 50, 100, 150, 200, 250 \& 300N. Analysis of molar tooth with implant at 300N shown in Fig. 5.

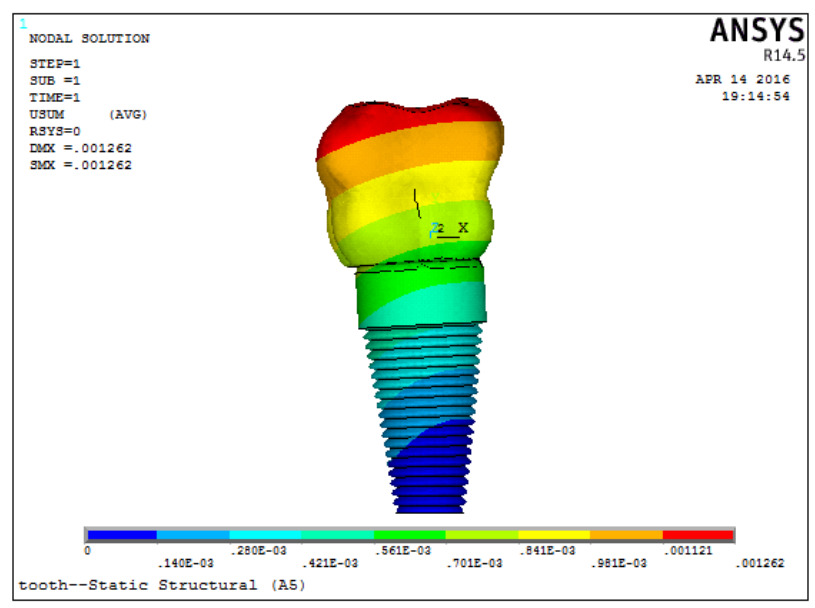

Fig. 5. Analysis of molar tooth with implant at 300N.

\section{EXPERIMENT AND RESULT}

The results obtained by different criteria for Titanium alloy (Ti-6Al-4V ELI) and Zirconia bio-inert materials. Comparison of same with the design admissible limits of biomaterials.

\section{A. Total Deformation Criteria}

Total deformation plot distribution of Ti-6Al-4V ELI and Zirconia molar tooth implant is shown in Fig. 6. It has been found that the deformation in Zirconia is less compared to Ti-6Al-4V ELI and can withstand maximum force with minimum total deformation. 


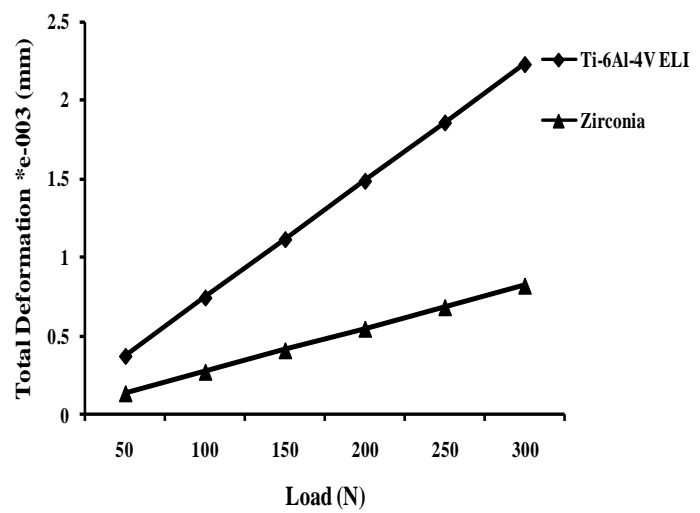

Fig. 6. Total Deformations plot distribution of Ti-6Al-4V ELI and Zirconia implant

\section{B. Maximum Principal Elastic Strain}

Maximum Principal Elastic Strain plot distribution of Ti-6Al-4V ELI and Zirconia molar tooth with implants is shown in Fig. 7. It has been found that the Elastic Strain induced in Zirconia is minimum compared to Ti-6Al-4V ELI. Hence Zirconia exhibits a superior characteristics than Ti-6Al-4V ELI.

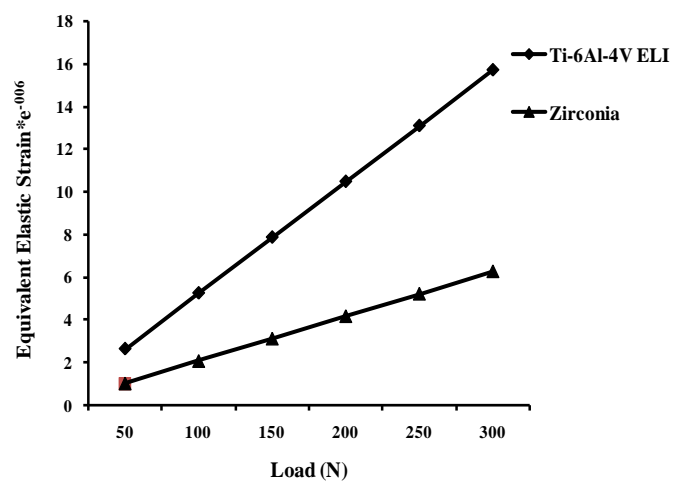

Fig. 7. Maximum Principal Elastic Strain plot distribution of Ti-6Al-4V ELI and Zirconia molar tooth with implant.

\section{Maximum Principal Stress}

Maximum Principal Stress plot distribution in Ti-6Al-4V ELI and Zirconia molar tooth with implant is shown in Fig. 8. From the above results it is found that principal stress induced in Zirconia is slightly higher than Ti-6Al-4V ELI and Zirconia withstand higher compressive strength than Ti-6Al-4V ELI.

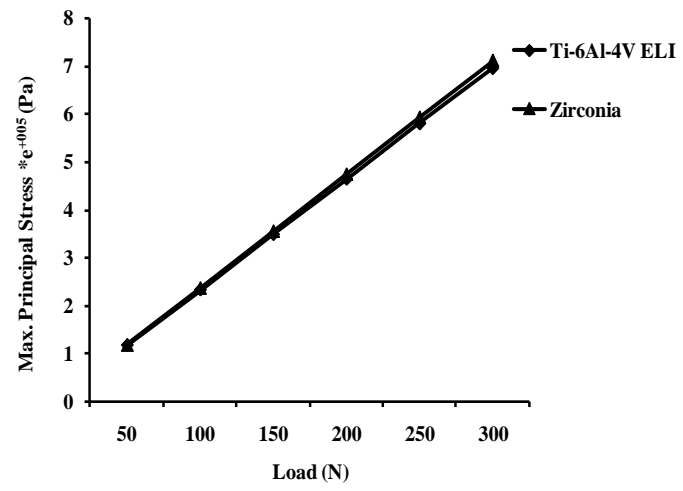

Fig. 8. Maximum Principal Stress plot distribution of Ti-6Al-4V ELI and Zirconia molar tooth with implant 


\section{Fatigue Analysis}

A good dental implant design should satisfy maximum fatigue life. This can be ensured by fatigue analysis. Fatigue analysis for Ti-6Al-4V ELI molar tooth with Ti-6Al-4V ELI implant and Zirconia molar tooth with Zirconia implant were carried out to evaluate factor of safety. Fatigue analysis was performed by utilizing the Von Mises stress obtained from static analysis. The stress life $(\mathrm{S} / \mathrm{N})$ approach is used to determine the fatigue life of the dental implant material, hence it is considered in the present work. Fatigue Analysis of Ti-6Al-4V ELI and Zirconia molar tooth with implant is shown in Fig. 9.

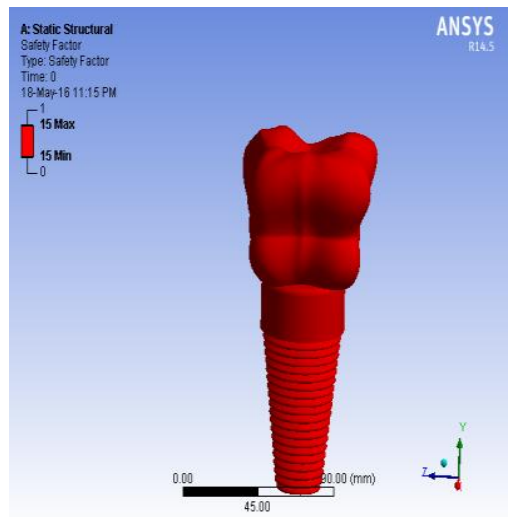

Fig. 9. Fatigue Analysis of Ti-6Al-4V ELI and Zirconia molar tooth with implant

The result showed that the maximum factor of safety was found to be 15 in both Ti-6Al-4V ELI and Zirconia implant, which is within the admissible limit for the safer design. As it was seen in previous research article [14], the fatigue analysis results were similar on Zirconia material. The result showed that fatigue resistance of Ti-6Al-4V ELI Bio-inert material was higher compared to Zirconia bio-inert material as shown Fig. 10.

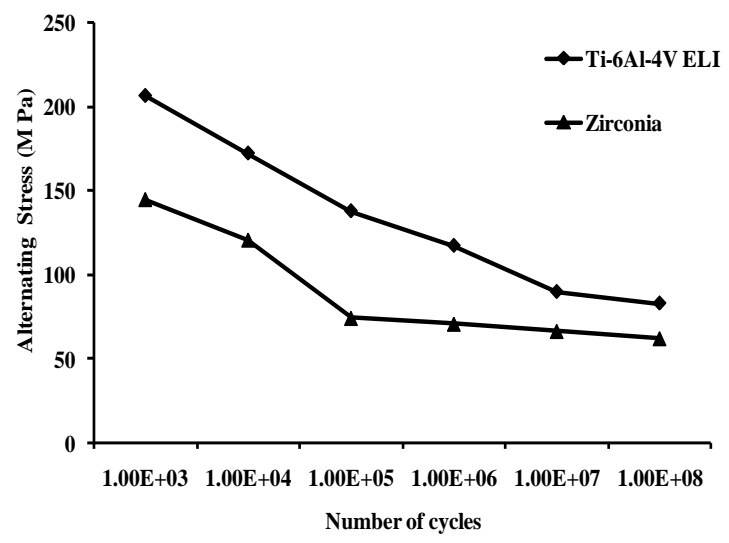

Fig. 10. S/N Curve of Ti-6Al-4V ELI and Zirconia Bio-inert material

age (d) Recovered watermark Image

\section{IV.CONCLUSION}

Accurate three-dimensional CAD model of Molar tooth with dental implant was created by CATIA V5 and converted to STL format for FE analysis. 3D stress analysis of two piece molar tooth with dental implant was successfully carried out on Zirconia and Ti-6Al-4V ELI model using FEA tool - Ansys under different loading condition from $50-300 \mathrm{~N}$ at the equal interval of $50 \mathrm{~N}$. The generated FEA model was most accurate to actual tooth model. Analysis of stress and total deformation distribution revealed that zirconia to be the best with stress $711.25 \mathrm{KPa}$ and total deformation $0.8221 \mathrm{e}-003 \mathrm{~mm}$ at maximum Load of $300 \mathrm{~N}$ compared to Ti-6Al-4V ELI with stress $696 \mathrm{KPa}$ and total deformation $2.2308 \mathrm{e}-003 \mathrm{~mm}$. Hence Zirconia with outstanding superior characteristics than Ti-6Al-4V ELI found to be the best alternate biomaterial suitable for dental implants, crown and bridges etc. 


\section{Finite Element Analysis Of Ti-6al-4v Eli And Zirconia Bio-Inert Material Used In Molar Tooth Dental Implant Application

\section{REFERENCES}

[1] A. Ahmad Jumah, M.N. Beekmans and J. David Wood, "Zirconia Implants: The new arrival in the armoury of successful aesthetic implant dentistry", Smile dental journal, vol. 2, 2012, pp. 12 - 24.

[2] B Andrea Motta, C. Luiz Pereira, R.C. Andreia, "Finite Element Analysis in 2D and 3D models for sound and restored teeth", ASM Handbook, Vol. 10, 2006, p. 329 - 339.

[3] K.J. Bathe, "Finite element procedures", Prentice Hall of India Pvt. Ltd., New Delhi, India, 1996, p. 25.

[4] D.H. Barnes, A. Moavenian, A. Sharma, S.M. Best, "Biocompatibility of ceramics, Materials for medical devices", ASM Handbook, Vol. 23, 2012, pp. $128-129$.

[5] Chiung Fang Wang, Heng Li Huang, Dan Jae Lin, Yen Wen Shen, Lih Jyh Fuh, Jui Ting Hsu, "Comparisions of maximum deformation and failure forces at the implant abutment interface of titanium implants between titanium alloy and zirconia abutments with two levels of marginal bone loss", Vol. 1, 2013, pp. 01 - 10.

[6] G.N. Colvin, B. London, "Titanium alloys, cast, Advances in titanium alloy casting technology", ASM Handbook, Vol. 44, 2010, pp. 2868 2874.

[7] Dattatraya Parle, Anirudha Ambulgeka, Ketan Gaikwad, "3D Modeling and Stress Analysis of Premolar tooth using FEA", Infosys High Trend Conference, India, 2012, p. 88.

[8] Davide Zaffe, Carlo Bertoldi and Ugo Consolo, "Element release from titanium devices used in oral and maxillofacial surgery", Biomaterials, Vol. 24, 2003, pp. 1093 - 1099.

[9] B. Freudenberg, Akiyoshi Osaka, "Aluminum Oxide - Biomedical applications, Materials for medical devices", ASM Handbook, Vol. 23, 2012, pp.267 - 269.

[10] F.N Hattab, A.S. Al-Momani, O.M. Yassin. Al-Omari MAO, A.H Hamasa and M.A. Rawashdeh, ":Crown diameters of deciduous teeth in Jordanians", Vol.13, 1999.

[11] Jie Yang, Hong Jun Xiang, “ A three-dimensional finite element study on the biomechanical behavior of an FGBM dental implant in surrounding bone", Journal of Biomechanics, Vol. 40, 2007, pp. 2377 - 2385.

[12] R.J. Kohal, M. Andreiotelli, "Fracture strength of zirconia implants after artificial aging", Clinical Implant Dent, Vol. 11, 2009 , pp. 158 166.

[13] Ravi Kant, N. Shrikrishna Joshi, S. Uday Dixit, "An integrated FEM-ANN model for laser bending process with inverse estimation of absorptivity", Mechanics of Advanced Materials and Modern Processes, Vol. 1, 2015, pp. 08 -15.

[14] S.H. Teoh, "Fatigue of Biomaterials: a review", Int. Journal of fatigue, Vol. 22, 2000, pp.825-837. 